
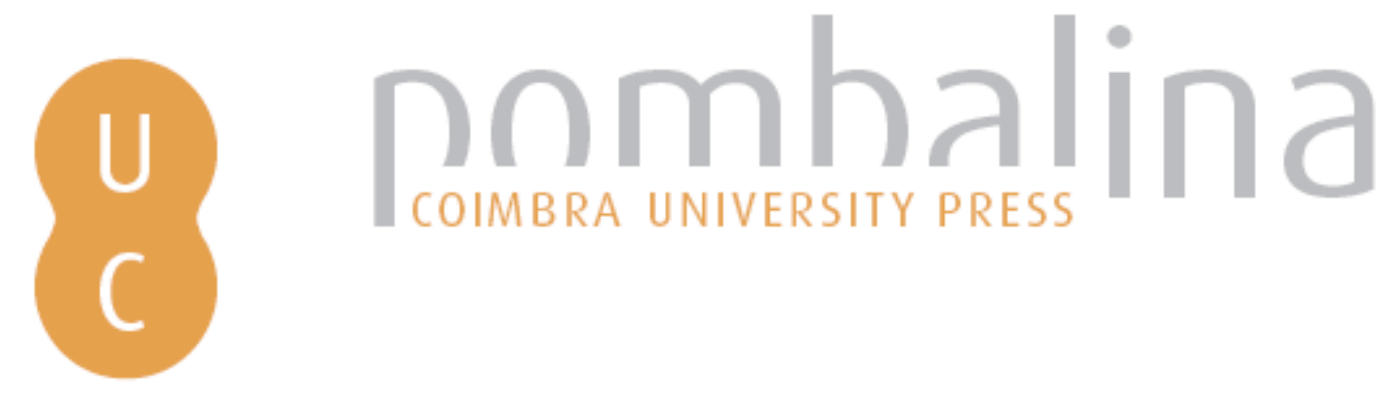

\title{
Populações rurais e os riscos frente à expansão do turismo: vertentes socioambientais e ressignificações da relação espaço-natureza
}
Autor(es):
Almeida, Germana Lima de; Rodrigues, Lea Carvalho
Publicado por: Imprensa da Universidade de Coimbra; RISCOS - Associação Portuguesa de Riscos, Prevenção e Segurança
URL persistente:
URI:http://hdl.handle.net/10316.2/34914
DOI:
DOI:http://dx.doi.org/10.14195/978-989-96253-3-4_114
Accessed : $\quad$ 26-Apr-2023 03:26:51

A navegação consulta e descarregamento dos títulos inseridos nas Bibliotecas Digitais UC Digitalis, UC Pombalina e UC Impactum, pressupõem a aceitação plena e sem reservas dos Termos e Condições de Uso destas Bibliotecas Digitais, disponíveis em https://digitalis.uc.pt/pt-pt/termos.

Conforme exposto nos referidos Termos e Condições de Uso, o descarregamento de títulos de acesso restrito requer uma licença válida de autorização devendo o utilizador aceder ao(s) documento(s) a partir de um endereço de IP da instituição detentora da supramencionada licença.

Ao utilizador é apenas permitido o descarregamento para uso pessoal, pelo que o emprego do(s) título(s) descarregado(s) para outro fim, designadamente comercial, carece de autorização do respetivo autor ou editor da obra.

Na medida em que todas as obras da UC Digitalis se encontram protegidas pelo Código do Direito de Autor e Direitos Conexos e demais legislação aplicável, toda a cópia, parcial ou total, deste documento, nos casos em que é legalmente admitida, deverá conter ou fazer-se acompanhar por este aviso.

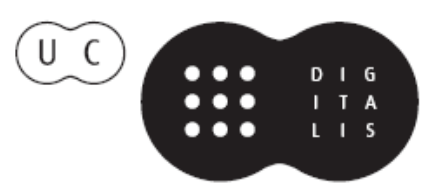



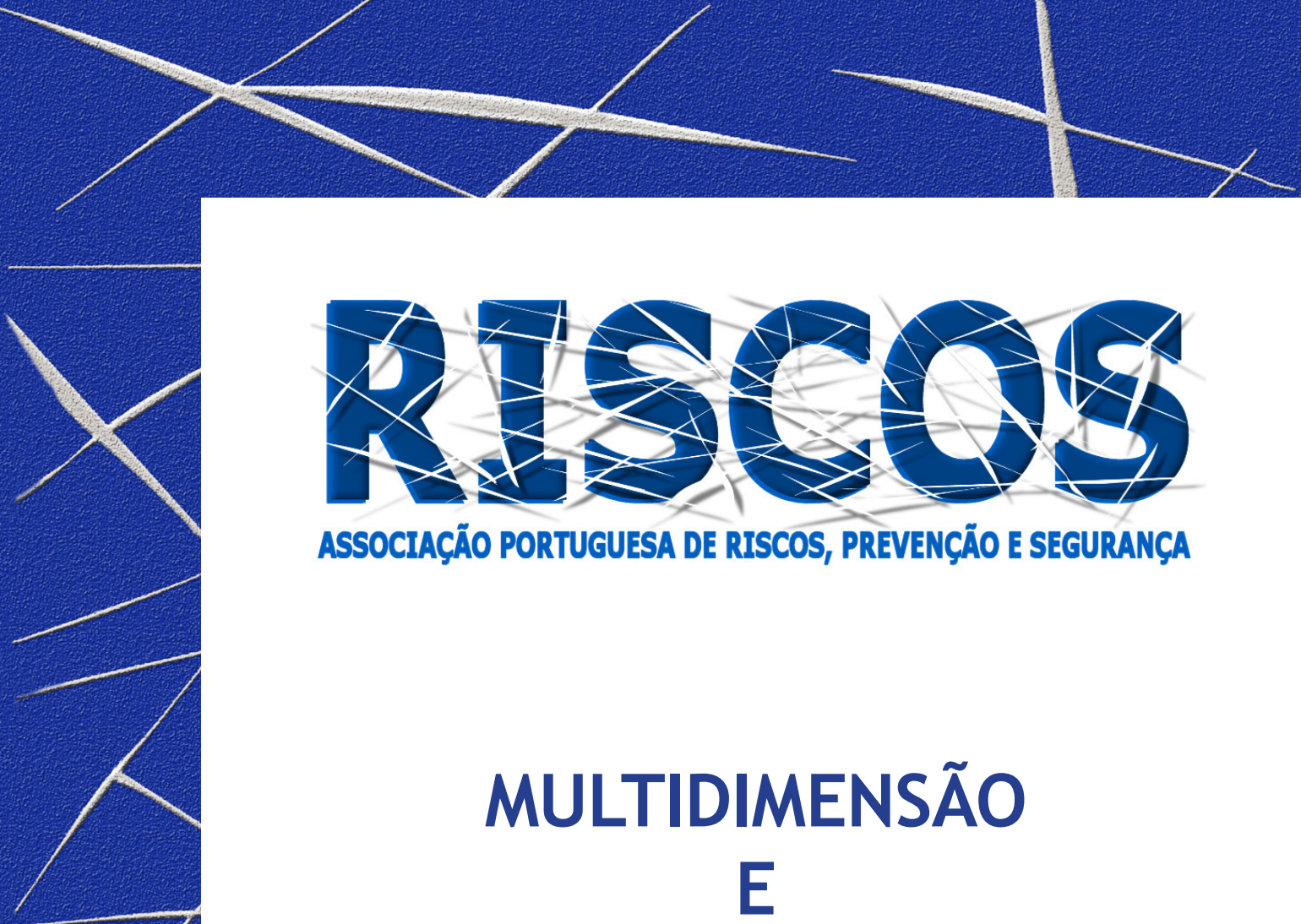

ASSOCIAÇÃO PORTUGUESA DE RISCOS, PREVENCCÃO E SEGURANÇA

MULTIDIMENSÃO

E
TERRITÓRIOS DE RISCO

III Congresso Internacional

I Simpósio Ibero-Americano

VIII Encontro Nacional de Riscos

Guimarães

2014 


\title{
POPULAÇÕES RURAIS E OS RISCOS FRENTE À EXPANSÃO DO TURISMO: VERTENTES SOCIOAMBIENTAIS E RESSIGNIFICAÇÕES DA RELAÇÃO ESPAÇO-NATUREZA
}

\author{
Germana Lima de Almeida \\ Universidade Regional do Cariri - URCA \\ germanalima@alu.ufc.br \\ Lea Carvalho Rodrigues \\ Universidade Federal do Ceará-UFC \\ leaufc@gmail.com
}

\begin{abstract}
RESUMO
Guaramiranga é um município serrano situado a 110 quilômetros da capital do estado do Ceará (Brasil), essencialmente ligado à agricultura desde o século XIX até o final da década de 1980 quando envolvia ainda 93\% de sua população nesta atividade. A partir de 1990 políticas públicas desestimularam o manejo agrícola convergindo estas populações para a atividade turística, alegando sua eficiência na geração de divisas e adequação aos novos preceitos de preservação ambiental. Após 24 anos de inserção do turismo, este artigo questiona a estratégia de sustentabilidade ecológica do modelo proposto - em diálogo com Diegues (1997) e Mowforth, Charlton e Munt (2008) -, contrapondo os benefícios anunciados às contradições advindas da atividade turística, sobretudo nos países do hemisfério Sul, que resultam, frequentemente, na degradação de espaços naturais e na segregação de suas populações locais, como observam Rodrigues e Alencar (2011), Ribeiro e Barros (1994), Lopez e Marin (2010).
\end{abstract}

Palavras-chave: Turismo, populações rurais, Guaramiranga (Ceará, Brasil), degradação ambiental, riscos sociais.

\section{Introdução}

No início da década de 1990, Giddens (1991) afirmava que vivemos num período de modernidade radicalizada, em que ocorre "um processo simultâneo de transformação da intimidade e de reorganização social global” (p.176), vivenciado num ambiente de riscos de alta-consequência. Nesta obra, claramente inspirada na Sociedade de Risco referida por Beck (2010), Giddens diz que "ameaças ecológicas são o resultado de conhecimento socialmente organizado, mediado pelo impacto do industrialismo sobre o meio ambiente material” (p.112), uma característica da contemporaneidade.

No mesmo período, juntamente às mudanças na esfera produtiva - redução das atividades primárias e ascensão do setor de serviços -, o turismo apontava como uma das atividades econômicas mais promissoras. Desde os anos 1970 esta atividade vinha sendo fortemente recomendada pelo Banco Mundial (BID) e o Banco Interamericano de Desenvolvimento (BIRD), aos países do hemisfério Sul que dispunham de atrativos naturais. 0 turismo era apresentado como uma excelente estratégia de desenvolvimento e os recursos para o investimento nesta atividade eram disponibilizados por estas agências, com o intuito de atuar em parceria com os governos nacionais.

Passados mais de quarenta anos, esta atividade econômica realmente prosperou, a ponto de tornar-se a que mais cresce em âmbito mundial, suplantando os resultados da indústria automobilística e de bens duráveis (Rodrigues, 2014). A Organização Mundial do Turismo (UNWTON, 2012) informa que, mesmo no contexto de crise mundial, o turismo continuou crescendo. Para Lopez e Marín (2010) o turismo é uma indústria global, pois envolve uma ampla 
e diversificada cadeia produtiva que articula países, economias, territórios e culturas, promovendo mobilidade crescente de capitais.

Em vista do exposto, o argumento deste artigo é que o turismo, assim como o industrialismo, impacta populações e meio ambiente e constitui um dos vetores de risco a se considerar, com importância, no cenário contemporâneo.

Como mostram Rodrigues e Santos (2010), o turismo, no Brasil, vem incentivando a especulação imobiliária em áreas litorâneas, afetando populações tradicionais bem como o ambiente. Ribeiro e Barros (1994) relatam, no caso mexicano, como populações indígenas mayas foram deslocadas de áreas atrativas ao capital turístico para locais interioranos, resultando em alterações linguísticas, no modo de vida, na organização social e na dieta alimentar. Mowforth, Charlton e Munt (2008) afirmam, ainda, que os benefícios para as populações desses países nem sempre se concretizam.

Neste artigo tomamos o caso específico de um município situado na região serrana do Ceará, com um passado marcado pela agricultura, e apreciamos os efeitos decorrentes da queda das atividades agrícolas e da ascensão do turismo na localidade.

\section{Características do município de Guaramiranga e de sua população}

Guaramiranga é um pequeno município brasileiro com 52 quilômetros quadrados de extensão e altitude máxima de 1.150 metros, situado a 110 quilômetros de Fortaleza, capital do estado do Ceará. Ali, desde o século XIX e até os anos 1980 a atividade agrícola foi a principal atividade econômica, chegando a ocupar até $93 \%$ de sua população economicamente ativa, já que as especificidades da cafeicultura e da geomorfologia local demandavam um intenso contingente humano nas plantações.

A lógica sociocultural que estrutura as populações rurais, conforme Durham (1973) e Woortmann \& Woortmann (1997), ressaltam a intensa coesão social destes grupos, acionando fortemente os laços de parentesco, as relações preferenciais e de reciprocidade no exercício de suas atividades produtivas. Tais características coadunam com um modelo de interação homem-natureza no qual o trabalho produz não apenas produtos para consumo e venda, mas também categorias sociais que, em sua ação simbólica, constroem saberes, signos, valores e sociabilidades.

$\mathrm{Na}$ década de 1990, contudo, a questão ambiental ganhou centralidade e atingiu as populações rurais da referida localidade. A criação de uma Área de Proteção Ambiental (APA) abarcou 92\% do município e tornou-se o principal instrumento na ressignificação da relação homem-natureza. A partir de então o foco era a conscientização quanto ao manejo da vegetação, ocorrendo a proibição de algumas práticas agrícolas, ao mesmo tempo em que eram estimuladas atividades diferenciadas, como: turismo, lazer, educação ambiental, etc. Dessa forma, destituiu-se o agricultor local de sua ancestral precedência sobre o uso, manejo e produção de saberes a partir da natureza, da vegetação e do espaço físico e social agrícola, historicamente constituído. 0 deslocamento das atividades agrícolas para as turísticas agiu diretamente na raiz cognitiva e subjetiva destas populações. A ressignificação do uso da natureza - de um bem a ser trabalhado e socializado, para um bem a ser mantido intocado (Diegues, 2001), reformulou também a lógica das relações socioculturais, desencadeando um processo mais profundo de transformações.

Dentre as políticas públicas foi implantado um Hotel Escola para a capacitação da população na nova modalidade econômica - mas sem êxito, conforme pudemos constatar empiricamente (Almeida, 2014). Vale destacar que as dificuldades de adaptação de populações rurais às atividades urbanas haviam sido apontadas por Durham (1973), sob o argumento de que o modelo 
sociocultural agrícola distancia suas populações do dinamismo exigido em sociedades urbanas capitalistas. A autora refere-se às relações de reciprocidade que cedem lugar, gradativamente, às relações formais próprias a um ambiente capitalista mais competitivo e individualista, bem como ao arcabouço cultural destas populações, frente a um sistema extremamente dinâmico e diversificado de ideias, trocas, hábitos, subjetividades e costumes. Constatamos que, quando se implementou o turismo em Guaramiranga, a imensa maioria desta população rural continuou desprovida de equipamentos e estratégias que thes possibilitassem a imersão numa dinâmica capitalista mais intensa, ancorada em instituições impessoais.

\section{Êxodo rural e conflitos socioespaciais: o novo espaço-natureza}

A década de 2000 representou mais turbulências na dinâmica de vida destes grupos: enquanto a mídia noticiava um fluxo de visitantes de até seis vezes o número da população local, no período carnavalesco, dados do Instituto Brasileiro de Geografia e Estatística (IBGE) detectaram um decréscimo populacional da ordem de quase 30\% entre os anos 2006 e 2007, situação que se manteve nos anos seguintes. Este declínio reflete o aquecimento da atividade imobiliária decorrente do turismo, com a diminuição das terras arrendáveis e das condições de moradia para estas famílias.

Simultaneamente, diversos imóveis historicamente ligados à economia agrícola local foram reformulados por órgãos públicos ou investidores privados para sua inserção na atividade turística, como é o caso de uma casa de farinha transformada em restaurante, um convento transformado em pousada, um núcleo de casas comerciais demolido para construção de um teatro para realização de festivais, etc. Destacamos, ainda, que tais reformulações provocaram - devido a sua altitude, paisagem florestal e clima ameno numa região semiárida - uma evocação às paisagens de países de clima temperado. A maioria dos restaurantes e estabelecimentos implantados se valem de referenciais europeus, na arquitetura e na culinária, inclusive com a realização de festivais gastronômicos com pratos típicos de vários países.

Por outro lado, o festival de Jazz \& Blues que ali se realiza anualmente no período do carnaval também se tornou um dos principais atrativos turísticos da cidade. 0 evento atrai visitantes de alto poder aquisitivo para usufruir da paisagem serrana que evoca o clima de países temperados o também um estilo musical estrangeiro. Esta criação de paisagens ou experiências exóticas, segundo Ribeiro e Barros (1994) são próprias do turismo e mudaram, além do espaço físico, também a imagem subjetiva (Urry, 2001) à qual este município passou a ser vinculado. Segundo Augé (1994), a acelerada reformulação espacial de lugares provoca certa crise de sentido em suas populações, pois estes espaços trazem em si características não apenas físicas, mas identitárias, relacionais e históricas com suas populações. Assim, a destituição destes imóveis de suas funções originais traz consigo a quebra desse referencial prístino.

Dadas as consequências da adequação dos equipamentos turísticos a áreas de preservação (Dias, 2003), foi observada em Guaramiranga a degradação do ecossistema, pois a agressão desencadeada pela potência acustica dos shows perturba a fauna local e também a poluição dos afluentes ou matas, pela visitação desordenada de turistas. Com o aquecimento do mercado imobiliário ocorre, ainda, flagrante desrespeito à legislação ambiental, com a construção de empreendimentos veranistas ou hoteleiros em áreas de preservação. Algumas destas ocorrências motivaram notificações do Ministério Público Estadual e Federal. Encontram-se, dentre os casos notificados, a devastação de uma encosta para a construção de um empreendimento residencial de alto luxo e o assoreamento de um rio para a construção de um conjunto de apartamentos. 


\section{Conclusão}

Os dados apresentados corroboram nosso argumento de que o turismo apresenta-se como uma atividade de risco para as economias locais, as populações e o ambiente. Retomamos nossas reflexões iniciais para indicar algumas propostas que buscam amenizar a intensidade dos riscos. Giddens (1991) propõe retomar algumas utopias, que ele classifica como realistas, que possibilitariam um sentido de segurança ontológica e a expectativa de estar em um mundo sob controle humano. Para ele, devem ser colocados limites ao processo de acumulação capitalista e as formas de redução dos riscos deveriam ter uma base planetária. Também imagina um sistema geral de cuidado planetário com vistas à preservação do "bem estar ecológico do mundo". De uma perspectiva mais prática, Veyret e Richemond (2007) afirmam a necessidade da gestão do risco, o que comporta a sensibilização para as ameaças, as estimativas de risco e a adoção de medidas para controlá-lo.

\section{Bibliografia}

Almeida, G.L. (2014). Das festividades aos festivais: uma etnografia sobre populações rurais e a inserção do turismo em Guaramiranga. Monografia de conclusão do Curso de Ciências Sociais, Universidade Federal do Ceará, 137 p.

Augé, M. (1994) - Não lugares: uma introdução a uma antropologia da supermodernidade. Campinas: Papirus, $111 \mathrm{p}$.

Beck, U. (2010). Sociedade de risco: rumo a uma outra modernidade. São Paulo: Ed.34, 384p.

Dias, R. (2003) - Turismo sustentável e meio ambiente. São Paulo: Ed. Atlas.

Diegues, A. C. S. (2001) - O mito moderno da natureza intocada. São Paulo: Hucitec, 169p.

Durham, E. R. (1973). A caminho da cidade. São Paulo: Ed. Perspectiva, 245p.

Giddens, A. (1991). As consequências da modernidade. São Paulo: Ed.UNESP, 177p.

Lopez , A.; Marín, G. (2010) Turismo, capitalismo y producción de lo exótico. Una perspectiva crítica para el estudio de la mercantilización del espacio y la cultura. Relaciones, 123, p.219-258.

Mowforth, M.; Charlton, C. \& Munt, Ian (2008). Tourism and Responsibility. Perspectives from Latin America and the Caribbean. New York: Routledge, $338 \mathrm{p}$.

Ribeiro, G. L.; Barros, F. L. (1994). A corrida por paisagens autenticas: turismo, meio ambiente e subjetividade na contemporaneidade. Série Antropologia, n 379, Brasília, Ed. Universidade de Brasília, p. 2-25.

Rodrigues, L. (2014). Turismo como estratégia de desenvolvimento na América Latina: dilemas e perspectivas de um modelo excludente. In Alba M.P.de Carvalho \& Francisco Uribam X. de Holanda, Brasil e América Latina: percursos e dilemas de uma integração. Fortaleza: Ed. UFC, p.455-477.

Rodrigues, L.C., Santos, P.A. (2012) Populações tradicionais, turismo e conflitos territoriais. Estudo etnográfico em Tatajuba, Ceará. In: MARANHÃO, Max Priorsky (org.) Povos e Comunidades Tradicionais no Ceará. Fortaleza, CE: Programa de Pós-Graduação em Políticas Públicas e Sociedade (GEPE/UECE), 2012, p.67-93.

UNWTO (2012). World Tourism Barometer, vol.10, november/2012.

Urry, J. (2001) - O olhar do turista:lazer e viagens nas sociedades contemporâneas. São Paulo, Studio Nobel, SESC, 231p.

Veyret, Y. \& Richemond, N.M. (2007). Representação, gestão e expressão espacial do risco. In Yvette Veyret (Org.), Os riscos:o homem como agressor e vítima do meio ambiente. São Paulo: Contexto, 2007, p.47-61.

Woortmann, E.F.; Woortmann, K. (1997) O trabalho da terra: a lógica e a simbólica da lavoura camponesa. Brasília, Ed. Universidade de Brasília. 